\title{
The air of Europe: where are we going?
}

\author{
Isabella Annesi-Maesano \\ Affiliation: Epidemiology of Allergic and Respiratory Disease Dept, IPLESP INSERM and UPMC Sorbonne
} Universities, Medical School Saint-Antoine, Paris, France.

Correspondence: Isabella Annesi-Maesano, Epidemiology of Allergic and Respiratory Disease Dept, IPLESP INSERM and UPMC Sorbonne Universities, Medical School Saint-Antoine, 27 rue Chaligny, 75012 Paris, France. E-mail: Isabella.annesi-maesanođinserm.fr

@ERSpublications

Air pollution in Europe: the impact of air pollution and a review of air quality guidelines http://ow.ly/PCwY30g9ear

Cite this article as: Annesi-Maesano I. The air of Europe: where are we going? Eur Respir Rev 2017; 26: 170024 [https://doi.org/10.1183/16000617.0024-2017].

ABSTRACT Air pollution constitutes one of the main threats to public health in Europe. Significant impacts on the health of Europeans in terms of morbidity and mortality have been observed, even in cases of low exposure and where pollutant levels are within limits set by the European Union (EU). The respiratory system is a primary target of the harmful effects of key air pollutants. Emissions of many air pollutants have decreased substantially over the past decades in Europe, resulting in diminished concentrations and improved air quality. However, in several European cities concentrations still exceed EU reference values and, more often, the stricter World Health Organization air quality guidelines for all regulated air pollutants (particles with 50\% cut-off aerodynamic diameters of 10 and $2.5 \mu \mathrm{m}$, nitrogen dioxide $\left(\mathrm{NO}_{2}\right)$, benzo[a]pyrene and ozone $\left(\mathrm{O}_{3}\right)$ ) except sulfur dioxide. In addition, current trends indicate that in the absence of substantial changes, particulate matter, $\mathrm{NO}_{2}$ and $\mathrm{O}_{3}$ will still exceed limits in 2020 . Additional efforts must be made to comply with current standards and guidelines. These should include a more accurate and detailed monitoring of air pollutants, reduction of emissions and individual behaviour changes.

\section{Introduction}

Air pollution constitutes one of the main environmental threats to Europeans. Hence the question "The air of Europe, where are we going?" This review describes the current air quality situation and the progression of air quality guidelines in Europe and presents possible solutions to reduce emissions and individual exposure in view of the prevention of air pollution-related diseases, in particular respiratory diseases.

\section{Respiratory effects of air pollution}

Air pollution harms human health in the short and long term. The World Health Organization (WHO) reports that each year $\sim 7$ million people die (one in eight of total global deaths) as a result of air pollution exposure [1]. In Europe, while air quality is slowly improving, air pollution remains the single largest environmental health hazard, resulting in a lower quality of life due to illness and an estimated 467000 premature deaths per year, as reported by the European Environment Agency (EEA) [2]. Inhalation is the first route of entry of air pollutants and, as a consequence, cardiopulmonary effects are the most evident effects of air pollution exposure, cardiac effects being due to translocation of certain air pollutants from the lungs into the circulatory system. In the past 10 years, the European Respiratory Journal has published almost 300 papers on air pollution-related respiratory effects, including a series of articles on this topic,

Received: March 162017 | Accepted after revision: Oct 072017

Conflict of interest: None declared.

Provenance: Commissioned article, peer reviewed.

Copyright CERS 2017. ERR articles are open access and distributed under the terms of the Creative Commons Attribution Non-Commercial Licence 4.0. 
and more recently a joint European Respiratory Society/American Thoracic Society policy statement on the adverse health effects of air pollution [3]. This statement reports recent data, updating and broadening previous knowledge on what constitute adverse effects of air pollution on respiratory health. In addition, many new biomarkers of respiratory effects have been developed and applied in air pollution studies. These include increased levels of markers of airway inflammation (e.g. polymorphonuclear leukocytes or inflammatory cytokines in bronchoalveolar lavage or sputum), increased levels of airway injury or inflammation in exhaled breath (e.g. increased acidity of exhaled breath or condensate or increased exhaled nitric oxide fraction) and increased levels of blood markers of lung injury (e.g. 8-isoprostanes, club cell secretory protein).

In terms of mortality, both short-term and long-term exposure to air pollution have been linked to mortality from respiratory infections, chronic obstructive pulmonary disease (COPD) and lung cancer [4-7]. In terms of morbidity, air pollution has been related to asthma attacks, exacerbations of COPD and idiopathic pulmonary fibrosis (IPF) and childhood respiratory infections [4, 7-10] following short-term exposure, and, albeit with less evidence, to the development of asthma, COPD and lung cancer following long-term exposure [11-14]. The respiratory disease burden in children due to air pollution is huge, with children dying from respiratory infections in their early years in developing countries [3]. More importantly, air pollution is responsible for intermediate respiratory phenotypes such as upper and lower respiratory symptoms [3], airway inflammation and decreased lung function and lung growth leading to respiratory health impairment [15-20]. In addition, and of high relevance in public health, there is evidence of increased incidence of preterm birth, low birthweight or growth restriction, leading to adverse respiratory outcomes, due to exposure to air pollution [3]. Lastly, recent evidence shows that air pollution is responsible for effects in organs other than the respiratory system, namely in those involved in comorbidities of respiratory diseases such as cardiovascular diseases, metabolic diseases, osteoporosis, rheumatoid arthritis and neurodegenerative disorders [21], thus supporting the adverse role of long-term exposure.

\section{Air pollution in Europe \\ Major outdoor air pollutants}

Air quality depends on the air pollutants chosen to be regulated and the systematicity of their monitoring. Major air pollutants monitored in Europe include gases such as nitrogen dioxide $\left(\mathrm{NO}_{2}\right)$, ozone $\left(\mathrm{O}_{3}\right)$, sulfur dioxide $\left(\mathrm{SO}_{2}\right)$ and benzo[a]pyrene $(\mathrm{BaP})$ and particulate matter. In Europe, $\mathrm{NO}_{2}$ pollutes the air mainly as a result of road traffic and energy production through fossil fuel combustion processes. At ground level, $\mathrm{O}_{3}$ is a gas that is formed from other air pollutants such as oxides of nitrogen $\left(\mathrm{NO}_{\mathrm{x}}\right)$ and volatile organic compounds (VOCs) under the action of light and which reacts with other air pollutants (nitric oxide) and biocontaminants (allergens and pollens). $\mathrm{O}_{3}$ distribution varies according to space and time of the day, with peaks in the afternoon. In Europe, $\mathrm{O}_{3}$ levels are lower in urban polluted areas than elsewhere, because it vanishes when it reacts with other pollutants. $\mathrm{SO}_{2}$ is emitted mainly from industry and its highest concentrations overall are found in Eastern Europe. BaP has been taken as an indicator for polycyclic aromatic hydrocarbons. Particulate matter is the sum of all solid and liquid particles suspended in air that result from both anthropogenic (traffic, domestic combustion, agricultural operations, industrial processes, combustion of wood and fossil fuels and construction and demolition activities) and natural (windblown dust, wildfires and volcano eruptions) activities. Particulate matter contains dust, soot, smoke, fly ash, aerosols, fumes, mists and condensing vapours, pollen, spores, plant and insect parts and liquid droplets. Particles have many different size ranges and vary in their chemical composition. Particles are considered primary or secondary, according to whether they are directly emitted from a stationary and mobile sources (primary particles) or formed in the air (secondary particles) by transformation of gaseous emissions. The contaminants, namely oxides of sulfur, $\mathrm{NO}_{\mathrm{x}}$, VOCs and ammonia, which help form secondary particulate matter, result from human and natural activities. In Europe, particles with a 50\% cut-off aerodynamic diameter of $10 \mu \mathrm{m}$ (PM10) and $2.5 \mu \mathrm{m}$ (PM2.5), the so-called fine particles, are monitored and regulated, the latter only recently and on an annual basis. In Europe, sulfates, nitrates and organic matter are the main components of particulate air pollution in terms of the mass of the particles. Although of relevance in terms of health implications, smaller particulate matter such as ultrafine particles (UFPs) of an aerodynamic diameter of $0.1 \mu \mathrm{m}$ are not yet regulated in Europe. UFPs have a negligible mass and therefore have to be counted. UFPs can be fabricated intentionally or are by-products, such as emissions from specific processes, combustion reactions or equipment such as printer toner and automobile exhaust fumes, automotive emissions being the major source in Europe. Hot volcanic lava, ocean spray and wood smoke are common natural sources of UFPs. Polycyclic aromatic hydrocarbons, some of which are strongly carcinogenic, are one class of compounds contained in the organic fraction of the fine particulate matter. The proportion of the organic fraction in particulate matter is known to vary with particle size. The ultrafine fraction is hypothesised to be the most important carrier of polycyclic aromatic hydrocarbons, since it possesses the highest specific surface area of particulate matter. 
The evolution of air pollution and air quality guidelines in Europe

As reported by the EEA [2], emissions of many air pollutants have decreased substantially in Europe over the past decades, resulting in diminished concentrations and improved air quality across the continent. Between 2000 and 2014, significant decreasing trends in the $\mathrm{PM} 10$ and $\mathrm{NO}_{2}$ annual mean concentrations were found for $75 \%$ of air quality monitoring stations. In the same period, $\mathrm{SO}_{2}$ concentrations were generally below the limit values for the protection of human health. Similarly, on average, concentrations tended to decrease between 2006 and 2014 for PM2.5 and between 2007 and 2014 for BaP. However, concentrations still exceed European Union (EU) reference values, and even more often the stricter WHO air quality guidelines (AQGs), which offer guidance on reducing the effects on health of air pollution (table 1) in several European cities for all air pollutants except $\mathrm{SO}_{2}$, promulgated by the European Commission in 2012, and by the WHO in 2016. Previous guidelines were presented in European Commission air quality directives in 1987, 2004 and 2008 and in 2005, 2012 and 2015 by the WHO.

The latest data available from the EEA Air Quality e-Reporting database [23] show that EU limit values were still not respected at one or more stations, in urban areas overall, in the EU 28 member states during 2014. To give some examples, in that year, annual EU limit value was widely exceeded in $4 \%$ of all the reporting stations for $\mathrm{PM} 10$ and in $12 \%$ of the stations for $\mathrm{NO}_{2}$. At the country level, concentrations of $\mathrm{PM} 2.5$ and $\mathrm{BaP}$ above the $\mathrm{EU}$ annual reference values were registered by four and 12 member states, respectively, and 21 member states registered concentrations of PM10 greater than the EU daily limit. In addition, 16 countries registered concentrations above the $\mathrm{EU}$ 8-h $\mathrm{O}_{3}$ target value for the protection of human health. Furthermore, current trends indicate that EU limit values of particulate matter, $\mathrm{NO}_{2}$ and $\mathrm{O}_{3}$ will still be exceeded in 2020 . This implies that additional efforts must be taken to comply with current EU standards.

\section{Level of individual exposure in Europe}

Available data indicate that a significant proportion of Europeans live in areas, especially cities, where concentrations of pollutants exceed those stated in air quality standards (table 2).

In 2014, according to EU reference limit values, the air pollutant to which the population was most exposed was $\mathrm{BaP}$, followed by $\mathrm{PM} 10, \mathrm{NO}_{2}, \mathrm{PM} 2.5, \mathrm{O}_{3}$ and $\mathrm{SO}_{2}$, whereas according to WHO AQGs it was $\mathrm{NO}_{2}$, followed by PM2.5 and $\mathrm{BaP}, \mathrm{PM} 10, \mathrm{SO}_{2}$ and $\mathrm{O}_{3}$. The stricter WHO AQGs indicate that, excluding $\mathrm{O}_{3}$, $49-98 \%$ of the population is exposed to levels above the guideline limit values. In the case of $\mathrm{O}_{3}$, one out of 10 individuals is exposed to hazardous levels of this air pollutant according to WHO AQGs.

\section{Preventing the effects of air pollution}

According to existing data, two types of actions have been implemented to reduce the impact of air pollution: the reduction of air pollution emissions and the reduction of the exposure of individuals to air pollution. Reduction of air pollution emissions and individual exposure may be implemented at three different levels, namely governmental, industrial and individual, through the implementation of targets for interventions and recommendations. The role of the European Community is to promote and support such actions.

In 2011-2013, the Commission conducted a review of EU air policy, which resulted in the adoption of the Clean Air Policy Package. As part of the package, the Commission proposed a Clean Air Programme for

TABLE 1 European Union (EU) reference values and World Health Organization (WHO) air quality guidelines (AQGs) for the main air pollutants [22]

\section{EU reference value}

\begin{tabular}{lc}
\hline PM2.5 & $25 \mu \mathrm{g} \cdot \mathrm{m}^{-3}$ annual mean \\
& $40 \mu \mathrm{g} \cdot \mathrm{m}^{-3}$ annual mean \\
PM10 & $50 \mu \mathrm{g} \cdot \mathrm{m}^{-3} 24-\mathrm{h}$ mean $\mathrm{not}$ to be exceeded on $>35$ days per year) \\
& $40 \mu \mathrm{g} \cdot \mathrm{m}^{-3}$ annual mean \\
$\mathbf{N O}_{2}$ & $200 \mu \mathrm{g} \cdot \mathrm{m}^{-3} 1-\mathrm{h}$ mean \\
& $120 \mu \mathrm{g} \cdot \mathrm{m}^{-3} 8-\mathrm{h}$ mean \\
$\mathbf{O}_{3}$ & $125 \mu \mathrm{g} \cdot \mathrm{m}^{-3} 24-\mathrm{h}$ mean $(\mathrm{not}$ to be exceeded on $>3$ days per year) \\
SO $_{2}$ & $1 \mathrm{ng} \cdot \mathrm{m}^{-3}$ annual mean \\
&
\end{tabular}

WHO AQGs

$$
\begin{gathered}
10 \mu \mathrm{g} \cdot \mathrm{m}^{-3} \text { annual mean } \\
25 \mu \mathrm{g} \cdot \mathrm{m}^{-3} 24-\mathrm{h} \text { mean } \\
20 \mu \mathrm{g} \cdot \mathrm{m}^{-3} \text { annual mean } \\
50 \mu \mathrm{g} \cdot \mathrm{m}^{-3} 24-\mathrm{h} \text { mean } \\
40 \mu \mathrm{g} \cdot \mathrm{m}^{-3} \text { annual mean } \\
200 \mu \mathrm{g} \cdot \mathrm{m}^{-3} 1-\mathrm{h} \text { mean } \\
100 \mu \mathrm{g} \cdot \mathrm{m}^{-3} 8-\mathrm{h} \text { mean } \\
20 \mu \mathrm{g} \cdot \mathrm{m}^{-3} 24-\mathrm{h} \text { mean } \\
500 \mu \mathrm{g} \cdot \mathrm{m}^{-3} 10-\text { min mean }
\end{gathered}
$$

PMx: particles with a $50 \%$ cut-off aerodynamic diameter of $\mathrm{x} \mu \mathrm{m} ; \mathrm{NO}_{2}$ : nitrogen dioxide; $\mathrm{O}_{3}$ : ozone; $\mathrm{SO}_{2}$ : sulfur dioxide; $\mathrm{BaP}$ : benzo[a]pyrene. 
TABLE 2 Percentage of the urban population exposed to air pollutants in the 28 European Union (EU) member states according to EU reference values for the main air pollutants and World Health Organization (WHO) air quality guidelines (AQGs) for 2014 [24]

Estimated exposure according to EU reference values
Estimated exposure according to WHO AQGs

\begin{tabular}{lcc}
\hline PM2.5 & 12 & 91 \\
$\mathrm{PM}_{10}$ & 21 & 63 \\
$\mathrm{NO}_{2}$ & 17 & 98 \\
$\mathbf{O}_{3}$ & 9 & 9 \\
$\mathrm{BaP}$ & 24 & 91 \\
$\mathrm{SO}_{2}$ & $<1$ & 49
\end{tabular}

Data are presented as \%. Concentrations of particles with a $50 \%$ cut-off aerodynamic diameter of $\mathrm{x} \mu \mathrm{m}$ $(\mathrm{PMx})$, nitrogen dioxide $\left(\mathrm{NO}_{2}\right)$, ozone $\left(\mathrm{O}_{3}\right)$ and sulfur dioxide $\left(\mathrm{SO}_{2}\right)$ are measured in $\mu \mathrm{g} \cdot \mathrm{m}^{-3}$; concentrations of benzo[a]pyrene (BaP) are measured in $\mathrm{ng} \cdot \mathrm{m}^{-3}$. Data from [25].

Europe, updating the 2005 Thematic Strategy on Air Pollution in order to set new objectives for EU air policy for 2020 and 2030. The main legislative instrument to achieve the 2030 objectives of the Clean Air Programme is directive 2016/2284/EU on the reduction of national emissions of certain atmospheric pollutants, which came into force on December 31, 2016. This directive sets national reduction commitments for the five pollutants $\left(\mathrm{SO}_{2}, \mathrm{NO}_{\mathrm{x}}\right.$, VOCs, ammonia and fine particulate matter) responsible for acidification, eutrophication and ground-level $\mathrm{O}_{3}$ pollution. The new directive ensures that the emission ceilings for 2010 set in the previous directive shall apply until 2020. Directive 2016/2284 transposes the reduction commitments for 2020 taken by the EU and its member states under the revised Gothenburg Protocol and sets more ambitious reduction commitments only for 2030. Unfortunately, the directive excludes methane from the scope of the proposal; however, it enables flexibilities in certain cases, such as problematic enforcement of source-based legislation, unforeseen events in energy supply and production systems and particularly cold winters or dry summers. Of note, as previously emphasised, the EU reference values for the main air pollutants are higher than the WHO AQGs. Therefore, additional initiatives to reduce air pollution emissions have to be promoted.

Control measures that reduce air pollutants emissions tend to have a beneficial impact on ambient air pollutant levels and health. This has been shown in terms of public health in Switzerland [26]. The reduction of air pollution can be achieved through industrial upgrading, vehicle and fuel renovation, alternative energies, improvements in public transportation, city development programmes to reduce transportation and increase pedestrian areas and systematic health education to reduce both air pollution emissions at individual level and personal exposure by avoiding polluted zones. Lowering of personal exposure can be obtained by adopting low-emission and more responsible mobility. As practical examples, extra steps to reduce air pollution emission include reducing the number of trips taken by car, by carpooling, using public transport, biking or walking whenever possible; using environmentally safe paints and cleaning products whenever possible; reducing or eliminating fireplace and wood stove use; avoiding burning leaves, trash and other materials; and avoiding fuel-powered lawn and garden equipment.

In this context, the groups of people that are more susceptible to suffer health effects due to air pollution have to be more protected. These include elderly people, children and people with obesity or pre-existing heart and lung disease (asthma, COPD and IPF). In educating patients, physicians should encourage awareness of daily air quality, which can be found in weather broadcasts, on websites or through the use of notifications provided via email or an app and should provide recommendations for reducing exposure by basing activity on the air quality and on the patient's level of risk. Other groups, such as socially disadvantaged and poorly educated populations, may be more vulnerable due to higher exposure. It is crucial to address these populations. For them, exposure diminution can be obtained through reduction of air pollution and city development.

To be effective, reduction actions must be supported by precise air quality monitoring. Accurate monitoring at the individual level is a crucial step in the prevention of the effects of air pollution. It must emphasised that air quality data represent levels at fixed air quality monitor stations situated in representative places according to EU legislation. These may not be sufficient to protect those who live far from these places or who commute. In fact, at the proximity level, ad hoc measurements or dispersion model estimations have indicated that levels of air pollutants have not diminished over time in several sites and in these same sites, the number of vehicles has increased. The final purpose of assessing air pollution 
should be to enable the use of personal remote sensors to monitor individual real-time exposure to major air pollutants, in order to better understand health effects and mechanisms and to prevent exacerbations of asthma, COPD and IPF.

\section{Conclusion}

Air pollution still constitutes one of the main environmental threats to Europeans. However, action to prevent its health effects is possible.

\section{References}

1 World Health Organization. 7 Million Premature Deaths Annually Linked to Air Pollution. www.who.int/ mediacentre/news/releases/2014/air-pollution/en Date last updated: March 25, 2014.

2 European Environment Agency. Premature Deaths Attributable to Air Pollution. www.eea.europa.eu/media/ newsreleases/many-europeans-still-exposed-to-air-pollution-2015/premature-deaths-attributable-to-air-pollution Date last updated: April 21, 2016.

3 Thurston GD, Kipen H, Annesi-Maesano I, et al. A joint ERS/ATS policy statement: what constitutes an adverse health effect of air pollution? An analytical framework. Eur Respir J 2017; 49: 1600419.

4 Atkinson RW, Kang S, Anderson HR, et al. Epidemiological time series studies of PM2.5 and daily mortality and hospital admissions: a systematic review and meta-analysis. Thorax 2014; 69: 660-665.

5 Pope CA 3rd, Burnett RT, Thun MJ, et al. Lung cancer, cardiopulmonary mortality, and long-term exposure to fine particulate air pollution. JAMA 2002; 287: 1132-1141.

6 Kurt OK, Zhang J, Pinkerton KE. Pulmonary health effects of air pollution. Curr Opin Pulm Med 2016; 22: $138-143$.

7 Goldizen FC, Sly PD, Knibbs LD. Respiratory effects of air pollution on children. Pediatr Pulmonol 2016; 51: 94-108.

8 Hekking PP, Bel EH. Developing and emerging clinical asthma phenotypes. J Allergy Clin Immunol Pract 2014; 2: 671-680.

9 Li MH, Fan LC, Mao B, et al. Short-term exposure to ambient fine particulate matter increases hospitalizations and mortality in COPD: a systematic review and meta-analysis. Chest 2016; 149: 447-458.

10 Ryerson CJ, Cottin V, Brown KK, et al. Acute exacerbation of idiopathic pulmonary fibrosis: shifting the paradigm. Eur Respir J 2015; 46: 512-520.

11 Anderson HR, Favarato G, Atkinson RW. Long-term exposure to air pollution and the incidence of asthma: meta-analysis of cohort studies. Air Qual Atmos Health 2013; 6: 47-56.

12 Schikowski T, Mills IC, Anderson HR, et al. Ambient air pollution: a cause of COPD? Eur Respir J 2014; 43: 250-263.

13 Song Q, Christiani DC, Wang X, et al. The global contribution of outdoor air pollution to the incidence, prevalence, mortality and hospital admission for chronic obstructive pulmonary disease: a systematic review and meta-analysis. Int J Environ Res Public Health 2014; 11: 11822-11832.

14 Raaschou-Nielsen O, Andersen ZJ, Beelen R, et al. Air pollution and lung cancer incidence in 17 European cohorts: prospective analyses from the European Study of Cohorts for Air Pollution Effects (ESCAPE). Lancet Oncol 2013; 14: 813-822.

15 Bromberg PA. Mechanisms of the acute effects of inhaled ozone in humans. Biochim Biophys Acta 2016; 1860: 2771-2781.

16 Ghio AJ, Smith CB, Madden MC. Diesel exhaust particles and airway inflammation. Curr Opin Pulm Med 2012; 18: $144-150$.

17 Valavanidis A, Fiotakis K, Vlachogianni T. Airborne particulate matter and human health: toxicological assessment and importance of size and composition of particles for oxidative damage and carcinogenic mechanisms. J Environ Sci Health C Environ Carcinog Ecotoxicol Rev 2008; 26: 339-362.

18 Gauderman WJ, Urman R, Avol E, et al. Association of improved air quality with lung development in children. N Engl J Med 2015; 372: 905-913.

19 Rice MB, Ljungman PL, Wilker EH, et al. Long-term exposure to traffic emissions and fine particulate matter and lung function decline in the Framingham Heart Study. Am J Respir Crit Care Med 2015; 191: 656-664.

20 Downs SH, Schindler C, Liu LJS, et al. Reduced exposure to PM10 and attenuated age-related decline in lung function. N Engl J Med 2007; 357: 2338-2347.

21 Guan WJ, Zheng XY, Chung KF, et al. Impact of air pollution on the burden of chronic respiratory diseases in China: time for urgent action. Lancet 2016; 388: 1939-1951.

22 European Parliament, Directorate-General for Internal Policies, Policy Department A: Economic and Scientific Policy. EU Air Quality Policy and WHO Guideline Values for Health. Brussels, European Union, 2014. www. europarl.europa.eu/RegData/etudes/STUD/2014/536285/IPOL_STU(2014)536285_EN.pdf

23 European Environment Agency. Air Quality e-Reporting (AQ e-Reporting). www.eea.europa.eu/data-and-maps/ data/aqereporting-2. Date last updated: October 30, 2017.

24 European Environment Agency. Air Quality in Europe - 2015 Report. Luxembourg, European Environment Agency, 2015. Available from: www.eea.europa.eu/publications/air-quality-in-europe-2015

25 European Environment Agency. Air Quality in Europe - 2016 Report. Luxembourg, European Environment Agency, 2016. Available from: www.eea.europa.eu/publications/air-quality-in-europe-2016

26 Künzli N, Ackermann-Liebrich U, Brändli O, et al. Clinically 'small' effects of air pollution on FVC have a large public health impact. Swiss Study on Air Pollution and Lung Disease in Adults (SAPALDIA) - team. Eur Respir J 2000; 15: 131-136. 